\title{
SIMULAÇÃO DOS IMPACTOS DAS MUDANÇAS CLIMÁTICAS GLOBAIS NA EVAPOTRANSPIRAÇÃO DE REFERÊNCIA DA BACIA AMAZÔNICA BRASILEIRA
}

\author{
GOMES, Welison Wendel Eufrásio - welissoneufrasio@hotmail.com \\ Universidade Federal de Minas Gerais / UFMG
}

\author{
LEITE-FILHO, Argemiro Teixeira - argemirotlf@gmail.com \\ Universidade Federal de Minas Gerais / UFMG \\ SOARES-FILHO, Britaldo Silveira - britaldo@csr.ufmg.br \\ Universidade Federal de Minas Gerais / UFMG
}

Submetido em: 25/05/2020

Aceito para publicação em: 19/03/2021

Publicado em: 28/04/2021

DOI: http://dx.doi.org/10.5380/abclima.v28i0.74406

\begin{abstract}
RESUMO: A intensificação do processo de aquecimento do planeta causado pelo aumento na emissão de gases do efeito estufa (GEE) representa inúmeros riscos para os ecossistemas naturais. Mudanças na composição atmosférica podem alterar variáveis climáticas em diversas regiões do planeta, dentre elas a Bacia Amazônica Brasileira $(B A B)$. Considerada a maior bacia hidrográfica do planeta, esta região influencia o clima de outras partes do Brasil e da América Latina. Portanto, alterações na BAB podem acarretar em desequilíbrios ambientais em outras regiões. Dentre os efeitos causadas pelas mudanças climáticas, estão as modificações nos padrões de evapotranspiração, importante reguladora do ciclo hidrológico. Neste artigo simulamos as alterações futuras na evapotranspiração de referência (ETo) na BAB decorrentes de um contínuo aumento nas emissões de GEE (cenário RCP 8.5). Utilizamos a plataforma Dinamica EGO para implementar um modelo espacialmente explícito baseado no método de PenmanMonteith padronizado pela FAO. A validação foi realizada comparando estatisticamente os resultados entre as simulações e as observações. Dessa forma, comprovamos que o modelo representa de forma próxima ao real o processo de evapotranspiração na BAB. A sazonalidade projetada da ETo se manteve estatisticamente similar à observada até o ano de 2050, com o aumento da ETo durante a estação seca e diminuição durante a estação chuvosa. A ETo apresentou um padrão de distribuição espacial com maiores valores na porção leste, se estendendo no sentido norte-sul. Este padrão acompanha a distribuição dos valores de temperatura e saldo de radiação, além de coincidir com o arranjo espacial do desmatamento. Um forçamento radiativo de $8,5 \mathrm{w} / \mathrm{m}^{2} \mathrm{em}$ todo o planeta poderá aumentar a ETo na BAB, devido à elevação nos valores de temperatura e saldo de radiação solar. Este aumento é mais evidente na região nordeste se estendendo progressivamente para o sudoeste da bacia. Ao longo do século 21 , as futuras alterações nos padrões de ETo podem trazer grandes problemas para as práticas agrícolas e para o abastecimento hídrico na BAB e em outras partes do País. Em suma, as mudanças climáticas globais, refletindo em alterações na ETo em conjunto com o aumento do desmatamento, podem acarretar em uma desregulação do balanço hídrico. Os nossos resultados reforçam a necessidade da adoção de ações governamentais efetivas com o objetivo de mitigar os efeitos das intensas emissões de GEE.
\end{abstract}

PALAVRAS-CHAVE: evapotranspiração, mudanças climáticas, floresta amazônica, modelagem ambiental. 


\section{SIMULATION OF THE IMPACTS OF GLOBAL CLIMATE CHANGE ON REFERENCE EVAPOTRANSPIRATION IN THE BRAZILIAN AMAZON BASIN}

ABSTRACT: The intensification of the global warming process caused by the increase in the emission of greenhouse gases (GHG) represents numerous risks for natural ecosystems. Changes in the atmospheric composition can alter climatic variables in several regions of the planet, among them the Brazilian Amazon Basin (BAB). Considered the largest hydrographic basin on the planet, this region influences the climate in other parts of Brazil and Latin America. Therefore, changes in BAB can lead to environmental imbalances in other regions. Among the effects caused by climate change, there are changes in the evapotranspiration patterns, an important regulator of the hydrological cycle. In this article, we simulate future changes in the reference evapotranspiration (ETo) at BAB resulting from a continuous increase in GHG emissions (scenario RCP 8.5). We use the Dinamica EGO environmental modeling platform to implement a spatially explicit model based on the Penman-Monteith method standardized by FAO. The validation was carried out by statistically comparing the results between the simulations and the observations. Thus, we prove that the model closely represents the evapotranspiration process at BAB. The projected seasonality of ETo remained statistically similar to that observed until the year 2050, with an increase in ETo during the dry season and a reduction during the rainy season. ETo showed a spatial distribution pattern with higher values in the eastern portion, extending north-south. This pattern follows the distribution of the temperature and radiation balance values, in addition to coinciding with the spatial arrangement of deforestation. A radiative forcing of $8.5 \mathrm{w} / \mathrm{m}^{2}$ across the planet will cause an increase in ETo in the BAB, as a result of the increase in temperature values and the balance of solar radiation. This increase is more evident in the northeast region, progressively extending to the southwest of the basin. Throughout the 21st century, future changes in ETo patterns can pose major problems for agricultural practices and water supply in BAB and other parts of the country. In short, global climate change, reflecting changes in ETo together with the increase in deforestation, they can lead to a deregulation of the water balance. Our results reinforce the need to adopt effective government actions in order to mitigate the effects of the intense GHG emissions.

KEYWORDS: evapotranspiration, climate change, Amazon rainforest, environmental modeling.

\section{SIMULACIÓN DE LOS IMPACTOS DEL CAMBIO CLIMÁTICO GLOBAL SOBRE LA EVAPOTRANSPIRACIÓN DE REFERENCIA EN LA CUENCA AMAZÓNICA BRASILEÑA}

RESUMEN: La intensificación del proceso de calentamiento global provocado por el aumento de la emisión de gases de efecto invernadero (GEI) representa innumerables riesgos para los ecosistemas naturales. Los cambios en la composición atmosférica pueden alterar las variables climáticas en varias regiones del planeta, entre ellas la Cuenca Amazónica Brasileña (BAB). Considerada la cuenca hidrográfica más grande del planeta, esta región influye en el clima de otras partes de Brasil y América Latina. Por tanto, los cambios en BAB pueden provocar desequilibrios medioambientales en otras regiones. Entre los efectos provocados por el cambio climático, se encuentran cambios en los patrones de evapotranspiración, importante regulador del ciclo hidrológico. En este artículo, simulamos cambios futuros en la evapotranspiración de referencia (ETo) en BAB como resultado de un aumento continuo de las emisiones de GEI (escenario RCP 8.5). Utilizamos la plataforma de modelado ambiental Dinamica EGO para implementar un modelo espacialmente explícito basado en el método Penman-Monteith estandarizado por la FAO. La validación se llevó a cabo comparando estadísticamente los resultados entre las simulaciones y las observaciones. Por lo tanto, demostramos que el modelo representa de cerca el proceso de evapotranspiración en BAB. La estacionalidad proyectada de ETo se mantuvo estadísticamente similar a la observada hasta el año 2050, con un aumento de ETo durante la época seca y una reducción durante la época de Iluvias. ETo mostró un patrón de distribución espacial con valores más altos en la porción oriental, extendiéndose de norte a sur. Este patrón sigue la distribución de los valores de 
balance de temperatura y radiación, además de coincidir con la disposición espacial de la deforestación. Un forzamiento radiativo de $8,5 \mathrm{w} / \mathrm{m}^{2}$ en todo el planeta provocará un aumento de ETo en el BAB, resultante del aumento de los valores de temperatura y del equilibrio de la radiación solar. Este aumento es más evidente en la región noreste, extendiéndose progresivamente hacia el suroeste de la cuenca. A lo largo del siglo XXI, los cambios futuros en los patrones de ETo pueden plantear problemas importantes para las prácticas agrícolas y el suministro de agua en BAB y otras partes del país. En resumen, el cambio climático global, que refleja cambios en ETo junto con el aumento de la deforestación, a una desregulación del balance hídrico. Nuestros resultados refuerzan la necesidad de adoptar acciones gubernamentales efectivas para mitigar los efectos de las intensas emisiones de GEI.

PALABRAS CLAVE: evapotranspiración, cambio climático, selva amazónica, modelación ambiental.

\section{INTRODUÇÃO}

A Bacia Amazônica (BA) - a maior bacia hidrográfica do planeta (SILVA et al., 2010) - bombeia grandes volumes de água para a atmosfera através do processo de evapotranspiração (ET). Este suprimento de umidade contribui para a formação de massas úmidas que se deslocam na orientação norte-sul da Cordilheira dos Andes, chegando aos estados do Centro-sul do Brasil, ao Caribe e Oceano Pacífico (MARENGO, 2018). Posteriormente, esta umidade retorna ao sistema por meio da precipitação (SPRACKLEN et al., 2012). Portanto, modificações nos padrões de ET na BA podem afetar os padrões de chuva em diversas regiões do planeta (O'CONNOR et al., 2019).

Estas alterações (naturais ou derivadas das atividades humanas), principalmente devido ao aumento nas emissões de gases do efeito estufa (GEE), aumentam a sensibilidade da BA às mudanças climáticas (ESPINOZA et al. 2014; MARENGO e ESPINOZA, 2015). O aumento nas emissões de GEE em associação com o desmatamento na BA representa inúmeros riscos para a região Amazônica (MALHI et al., 2008), afetando o processo de ET regional (FEARNSIDE, 1995) e consequentemente afetando as localidades climaticamente conectadas.

Tais distúrbios afetam a agricultura e o abastecimento de água dos reservatórios urbanos. A ET é uma variável fundamental para estimar a exigência hídrica das culturas, além de fornecer subsídio para o dimensionamento de sistemas de bombeamento, adução e distribuição de água. Além da influência nos padrões de chuva e consequentemente no abastecimento hídrico, a ET também é um importante indicador do funcionamento do Ecossistema Amazônico (MAEDA et al., 2017). Estudos comprovam que a ET está associada à riqueza de espécies em uma determinada região (CURRIE, 1991; DINIZ-FILHO et al., 2003). A diminuição da ET e a consequente elevação na mortalidade das plantas pode implicar na redução de espécies animais dependentes destas espécies (MACARTHUR e MACARTHUR, 1961), aumentando assim o desequilíbrio ecológico. Por outro lado, a elevação da ET também causa impactos nos ecossistemas e na biodiversidade. Além disso, o aumento da ET poderá causar danos à vegetação com raízes pouco profundas, uma vez que a ET retiraria água das camadas mais superficiais do solo (CARVALHO, 2011) e afetar o ciclo global do carbono, reforçando um feedback positivo às mudanças climáticas (MAEDA et al., 2017).

Ao longo das últimas décadas diversos trabalhos procuraram elucidar o comportamento da ET na região Amazônica (WERTH e AVISSAR, 2004; HASLER 
e AVISSAR, 2007; SILVA JÚNIOR et al., 2017; MAEDA et al., 2017; O'CONNOR et al., 2019). Apesar dos recentes esforços para demonstrar o efeito da ET nos diversos processos ecossistêmicos, ainda são escassas as ferramentas capazes de estimá-la utilizando dados in situ ou provenientes de sensoriamento remoto (XU et al., 2019). Poucos estudos apresentam um grid de alta resolução espacial com valores de ET para a BA. Ainda mais escassos são os trabalhos com projeções espacialmente explícitas da ET considerando o aumento das concentrações de GEE ao longo do século XX. Estas alterações, além de afetarem a manutenção de diversos mecanismos ambientais na BA, influenciam os padrões climáticos regionais e globais (SPRACKLEN et al., 2012).

Diante destas lacunas, da notável influência da BA no clima de outras regiões (MARENGO, 2006; MARENGO, 2005; SPRACKLEN et al., 2012) e da importância da ET na determinação da capacidade de reservatórios, abastecimento hídrico e da agricultura, objetivamos: (I) Revisitar a sazonalidade e a variabilidade espacial da evapotranspiração de referência (ETo) na Bacia Amazônica Brasileira (BAB) de forma espacialmente explicita; (II) Avaliar os efeitos do aumento na concentração média de GEE na atmosfera causados por uma aumento na concentração média de dióxido de carbono correspondente a um forçamento radiativo de 8,5 watts por metro quadrado em todo o planeta, o que levaria a um aumento na temperatura média global de cerca de $5^{\circ} \mathrm{C}$ até 2100 e (III) Apresentar um modelo espacialmente explícito que possibilite estimativas futuras da ETo na BAB considerando cenários futuros de mudanças climáticas globais.

\section{DADOS E MÉTODOS}

\subsection{REGIÃO DE ESTUDO}

A área de estudo compreende toda a extensão da Bacia Amazônica situada no território brasileiro (Figura 1). A BAB possui aproximadamente 4 milhões de $\mathrm{km}^{2}$ localizados entre as coordenadas $47^{\circ}$ a $75^{\circ}$ de longitude oeste e $6^{\circ}$ de latitude norte a $17^{\circ}$ de latitude sul. Esta região cobre totalmente os estados do Acre, Amazonas, Rondônia, Roraima, Amapá e parcialmente os estados do Pará e Mato Grosso. 


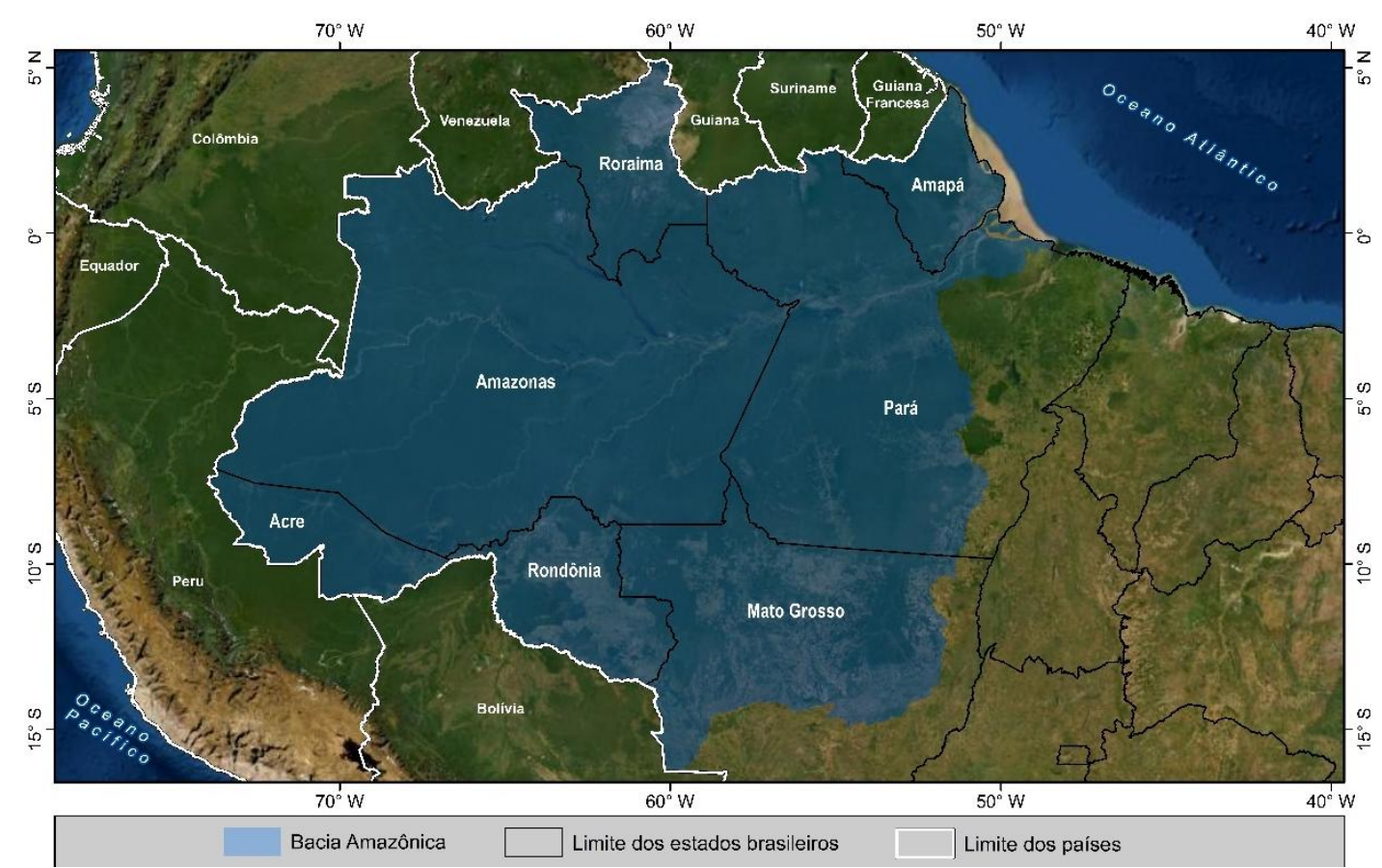

Figura 1 - Bacia Amazônica situada no território brasileiro.

A BAB possui características que dão maior relevância aos resultados: (I) $A B A B$ desempenha um importante papel na regulação do clima sul-americano devido à sua influência no ciclo hidrológico regional (MARENGO e SOUZA, 2018; SPRACKLEN et al., 2012). Cerca de $30 \%$ a $50 \%$ da precipitação na BA provém da água reciclada através da ET (SALATI et al, 1979; DIRMEYER et al., 2014), e parte desta umidade é transportada para outras localidades (MARENGO e SOUZA, 2018). (II) A BAB possui um forte acoplamento entre o clima e a biosfera. Mudanças na cobertura do solo (particularmente o desmatamento) alteram a ET, afetando o balanço de energia e o ciclo hidrológico (MARENGO, 2006). Demonstrar as mudanças nos padrões de ETo causados pelo aumento na concentração de GEE reforça o quão agravante é o desmatamento ao intensificar os efeitos das mudanças climáticas globais; (III) A BAB, especificamente a Floresta tropical, poderá enfrentar um rigoroso processo de savanização, o que a tornará mais seca e quente (MARENGO, 2006). Simular a ETo na Bacia Amazônica sob cenários de mudanças climáticas é, então, imprescindível para a elaboração de estratégias de adaptação e prevenção.

\subsection{DADOS}

Modelamos a ETo considerando um cenário de mudanças climáticas globais com concentração média de dióxido de carbono alcançando um forçamento radiativo de $8,5 \mathrm{w} / \mathrm{m}^{2}$. Para isso foram utilizadas variáveis climáticas em formato raster provenientes da Fase 5 do Coupled Model Intercomparison Project (CMIP5), elaborado pelo IPCC (Tabela 1). Utilizamos os dados provenientes do modelo climático Hadgem2-es, desenvolvido pelo UK Met Office Hadley Center for Climate Science and Services. Estudos anteriores demonstraram que este modelo possui bom desempenho em simular os padrões 
climáticos na América do Sul (GULIZIA e CAMILLONI, 2014; ALVES et al., 2012).

Tabela 1 - Variáveis meteorológicas utilizadas para o cálculo da ETo e suas respectivas unidades.

\begin{tabular}{lc}
\hline \multicolumn{1}{c}{ Variável } & Unidade \\
\hline Umidade relativa (UR) & $\%$ \\
$\begin{array}{l}\text { Radiação solar incidente (Rs) } \\
\text { Radiação solar incidente na ausência de } \\
\text { nuvens (Rso) }\end{array}$ & $\mathrm{W} \mathrm{m} \mathrm{m}^{-2}$ \\
$\begin{array}{l}\text { Velocidade do vento próxima à } \\
\text { superfície }\left(\mathrm{U}_{2}\right)\end{array}$ & $\mathrm{M} \mathrm{s}^{-1}$ \\
$\begin{array}{l}\text { Temperatura do ar }(\mathrm{T}) \\
\text { Temperatura do ar mínima (Tmin) }\end{array}$ & Kelvin \\
Temperatura do ar máxima (Tmax) & Kelvin \\
\hline
\end{tabular}

As projeções climáticas utilizadas no CMIP5 foram desenvolvidas utilizando a nova geração de cenários denominados Representative Concentration Pathways (RCP's). No Quinto Relatório de Avaliação do Painel Intergovernamental sobre Mudanças Climáticas (AR5) foram apresentados quatro cenários RCP's que descrevem diferentes futuros climáticos de acordo com a variação da concentração de GEE na atmosfera até o ano de 2100. São eles: um cenário de mitigação rigoroso (RCP 2.6), dois cenários intermediários (RCP 4.5 e RCP 6.0) e um cenário de altas emissões (RCP 8.5). Utilizamos o RCP 8.5, visto que, este cenário é consistente com as emissões cumulativas de $\mathrm{CO}_{2}$ dos últimos 15 anos e com os compromissos governamentais assumidos pelos países até 2050 (SCHWALM et al., 2020). Verifica-se uma probabilidade igual ou superior a $35 \%$ das concentrações excederem este cenário (CHRISTENSEN et al., 2018), demonstrando assim que as demais trajetórias de emissões estão se tornando irrealistas.

Além dos dados meteorológicos provenientes do CMIP5, utilizamos: Dados de ETo observados provenientes do banco de dados Daily gridded meteorological variables in Brazil (1980-2013) (XAVIER et al, 2015), para a validação dos resultados simulados pelo modelo, dados de altimetria provenientes do SRTM (Shuttle Radar Topography Mission) e compilados pela EMBRAPA (Empresa Brasileira de Pesquisa Agropecuária) para a estimativa da pressão atmosférica local e dados de precipitação relativos à normal climatológica atual (1981-2010) proveniente das 34 estações meteorológicas do INMET (Instituto Nacional de Meteorologia) instaladas na região de estudo como auxílio na interpretação dos resultados.

\subsection{MODELAGEM ESPACIALMENTE EXPLÍCITA DA ETO NA BACIA AMAZÔNICA BRASILEIRA}

Implementamos um modelo espacialmente explícito que represente fisicamente os processos da ETo na BAB (nomeamos o modelo como EER-PM, 
acrônimo da expressão "Estimativa da Evapotranspiração de Referência Penman-Monteith"). O EER-PM é constituído por dez módulos (Figura 2): dois deles destinados à conversão das unidades de medida e sete destinados ao cálculo das variáveis de input, além do módulo central que aplica a equação de Penman-Monteith para o cálculo da ETo.

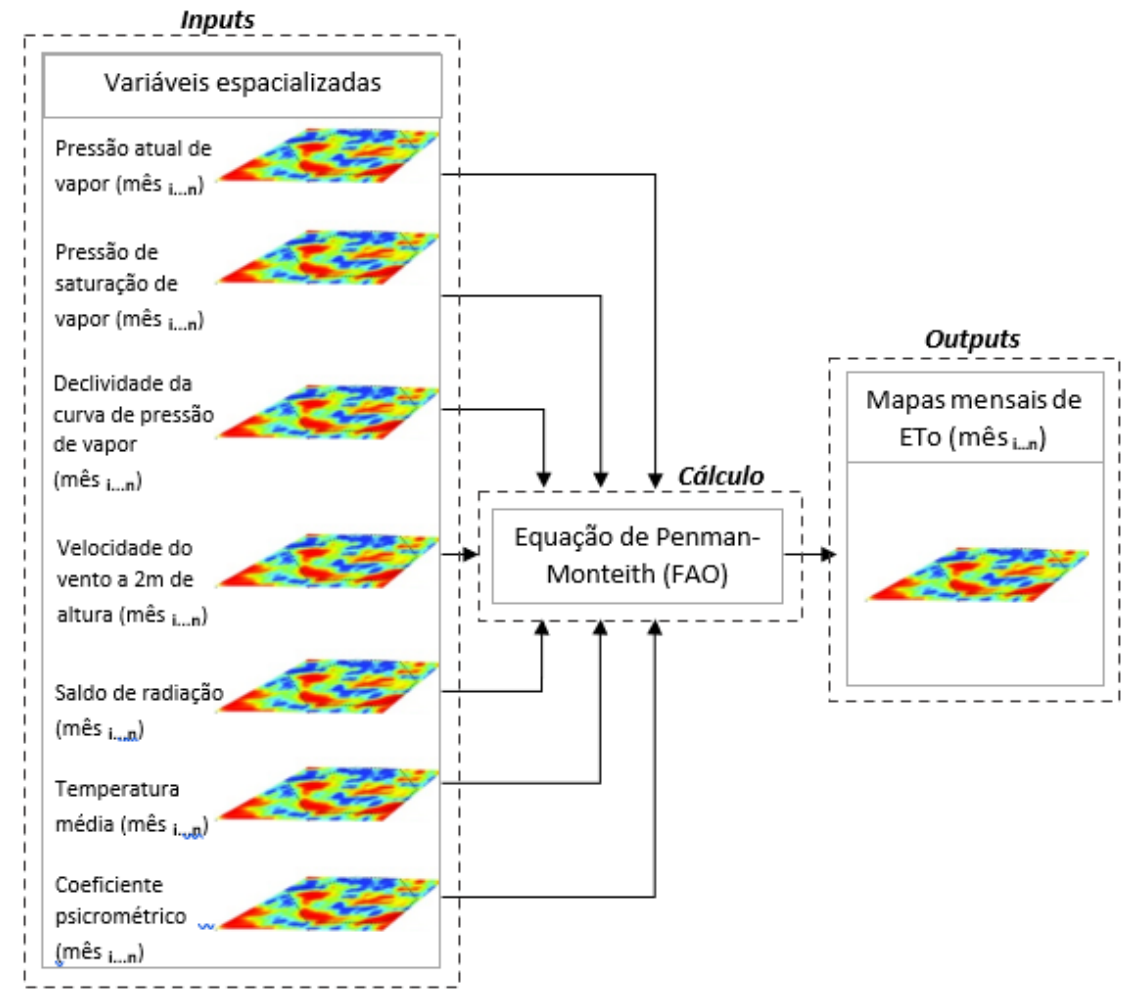

Figura 2 - Estrutura do modelo EER-PM implementado para automatizar o cálculo das estimativas de ETo na BAB.

O método de Penman-Monteith (MONTEITH, 1965) parametrizado pela Food and Agriculture Organization of the United States (FAO) (Equação 1; ALLEN et al., 1998) parte de uma representação dos fatores físicos e fisiológicos que comandam o processo de ET. Esta representação considera todos os parâmetros que governam as trocas de energia e o fluxo de calor latente. Selecionamos este método por dois motivos principais: (I) A maioria dos parâmetros necessários para os cálculos podem ser medidos ou estimados a partir de dados meteorológicos (ALLEN et al., 1998); e (II) Estudos prévios indicam que esta metodologia é considerada uma das formas mais apropriados para a estimativa da ETo na região amazônica (SILVA JúNIOR et al., 2017).

$$
\text { ETo }=\frac{0.408 \Delta(R n-G)+\frac{\gamma 900 u_{2\left(e_{S}-e_{a}\right)}}{T+273}}{\Delta+\gamma\left(1+0.34 u_{2}\right)} \quad(\text { Equação 1) }
$$

Onde: $\Delta$ é a declividade da curva de pressão de vapor em relação à temperatura $\left(\mathrm{kPa}{ }^{\circ} \mathrm{C}^{-1}\right) ; \mathrm{R}_{\mathrm{n}}$ é o saldo de radiação diário $\left(\mathrm{MJ} \mathrm{\textrm {m } ^ { - 2 }}\right.$ dia $\left.^{-1}\right) ; \mathrm{G}$ é o fluxo total diário de calor do solo $\left(\mathrm{MJ} \cdot \mathrm{m}^{-2}\right.$. dia $\left.{ }^{-1}\right) ; \gamma$ é o coeficiente psicrométrico $\left(\mathrm{kPa}{ }^{\circ} \mathrm{C}^{-1}\right) ; \mathrm{u}_{2}$ é a velocidade do vento a $2 \mathrm{~m}$ de altura do solo $\left(\mathrm{m} . \mathrm{s}^{-1}\right)$; T é a temperatura média do $\operatorname{ar}\left({ }^{\circ} \mathrm{C}\right) ; \mathrm{e}_{\mathrm{s}}$ é a pressão de saturação de vapor $(\mathrm{kPa})$ e $\mathrm{e}_{\mathrm{a}}$ é a pressão atual de 
vapor ( $\mathrm{kPa})$. Devido aos baixos valores de fluxo total de calor do solo diário (G) normalmente registrados e por não haver medições disponíveis, este foi considerado igual a zero conforme recomendado por Allen et al. (1998).

Todas as variáveis foram recortadas para a área de estudo e tiveram sua resolução espacial reamostradas para 500 metros, permitindo e facilitando a aplicação deste modelo como módulo acoplado a outros modelos ambientais, como por exemplo, na simulação de focos de calor e propagação de incêndios florestais (a exemplo do modelo FISC - Fire Ignition, Spread and Carbon components; SOARES-FILHO et al., 2012; BRANDO et al., 2020). As variáveis de radiação (Rs e Rso) e temperatura (média, máxima e mínima) provenientes do modelo climático Hadgem2-es tiveram as suas unidades previamente convertidas (Watts $/ \mathrm{m}^{2}$ para $\mathrm{MJ} / \mathrm{m}^{2}$ e Kevin para Celsius, respectivamente). Para a estimativa da pressão atmosférica local (em cada pixel) utilizamos dados de altimetria provenientes do SRTM conforme demonstrado na equação 2.

$$
\text { Patm }=101,3\left(\frac{293-0,0065 z}{293}\right)^{5,26} \text { (Equação 2) }
$$

Onde: Patm é a pressão atmosférica local (em kPa) e z é altitude média de cada pixel.

A Figura 3 ilustra o esquema de cálculo usado nas estimativas da ETo pixel a pixel utilizando o método de Penman-Monteith parametrizado pela FAO (ALLEN, 1998).

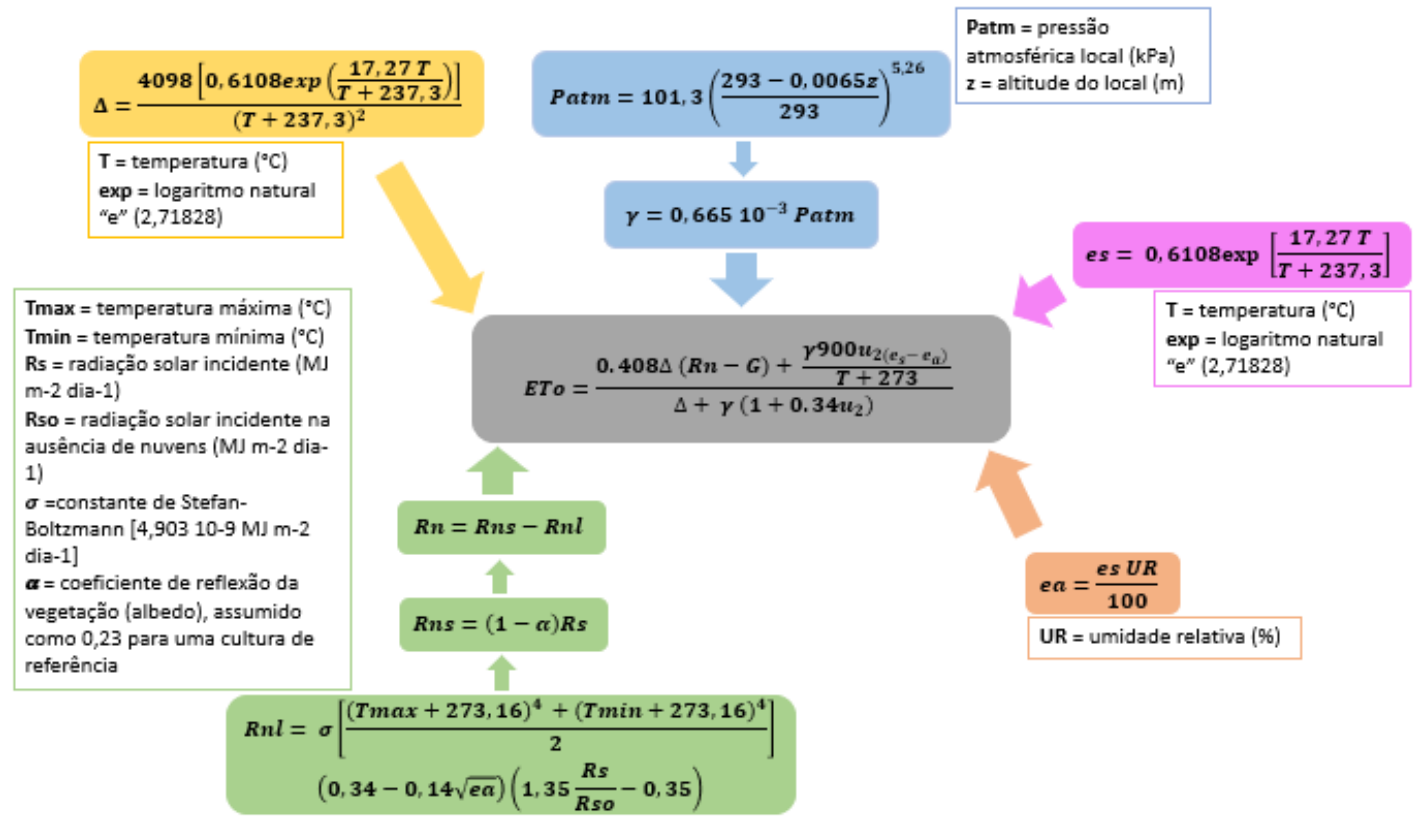

Figura 3 - Esquema de cálculo usado nas estimativas da ETo pixel a pixel utilizando o método de Penman-Monteith parametrizado pela FAO.

Todo o processo de modelagem foi realizado utilizando a plataforma DINAMICA EGO (dinamicaego.com; RODRIGUES et al. 2007; SOARES-FILHO et al. 2019). Este freeware é uma avançada ferramenta destinada à modelagem de sistemas ambientais. Inicialmente concebido como uma ferramenta destinada à investigação de trajetórias de paisagens e dinâmica de fenômenos espaciais, ao 
longo do seu desenvolvimento, o DINAMICA EGO englobou uma série de aplicações em diversos campos das ciências ambientais.

\subsection{VALIDAÇÃO DAS ESTIMATIVAS DA ETO OBTIDAS PELO MODELO EER-PM}

O modelo EER-PM foi validado em dois momentos. Em ambos utilizamos valores observados como entradas para o cálculo da ETo e estas estimativas foram comparadas com os dados de ETo observados. Na primeira validação avaliamos a precisão das estimativas de ETo utilizando como entradas os valores hipotéticos das variáveis envolvidas no cálculo da ETo fornecidos e previamente validados pela Empresa Brasileira de Pesquisa Agropecuária (EMBRAPA; CONCEIÇÃO, 2006). A segunda validação foi realizada a partir da comparação entre os valores de ETo estimados pelo modelo EER-PM no período simulado (1995 a 2005) com os valores observados obtidos por Xavier et al (2015) para o mesmo período. Ou seja, simulamos uma nova série de dados de ETo na BAB diferente daquela utilizada na etapa de construção e calibração do modelo em ambas formas de validação.

A comparação entre os valores simulados e observados foi realizada por meio: (I) das estatísticas de ajustamento $\left(\mathrm{R}^{2}\right)$; (II) do teste $\mathrm{t}$ de Student para comparação entre médias (utilizando o p-valor); (III) da correlação de Spearman (Rs); e (VI) da análise gráfica da correlação entre o comportamento sazonal das médias mensais de ETo encontradas nos dados observados e aquelas simuladas pelo modelo EER-PM.

\section{RESULTADOS E DISCUSSÃO}

\subsection{VALIDAÇÃO DAS PROJEÇÕES CALCULADAS PELO MODELO EER-PM}

Ao comparar os valores de ETo simulados pelo modelo EER-PM e as observações reais, verificamos que o modelo representa de forma próxima ao real a evapotranspiração na BAB. O resultado do teste t de Student indica que as médias de ETo simuladas pelo modelo para o período de 1995 a 2005 são estatisticamente iguais às médias observadas por Xavier et al. (2015) nestes mesmos anos. Ou seja, temos evidências de que os valores de ETo calculados pelo modelo EER-PM são, em média, iguais aos valores observados por Xavier e colaboradores com um nível de $95 \%$ de certeza. Obtivemos uma alta correlação segundo o teste de Spearman (Rs $=0,65$ ), o que indica que, quando as observações de ETo feitas por Xavier et a. (2015) aumentam, os valores estimados pelo modelo EER-PM também crescem. Por fim, verificamos também um ajustamento linear mediano entre os dois períodos $\left(R^{2}=0,45\right.$; Figura 4) entre os valores simulados e observados, indicando o quão próximos os dados estão da linha de regressão linear ajustada entre os dados observados e simulados. 


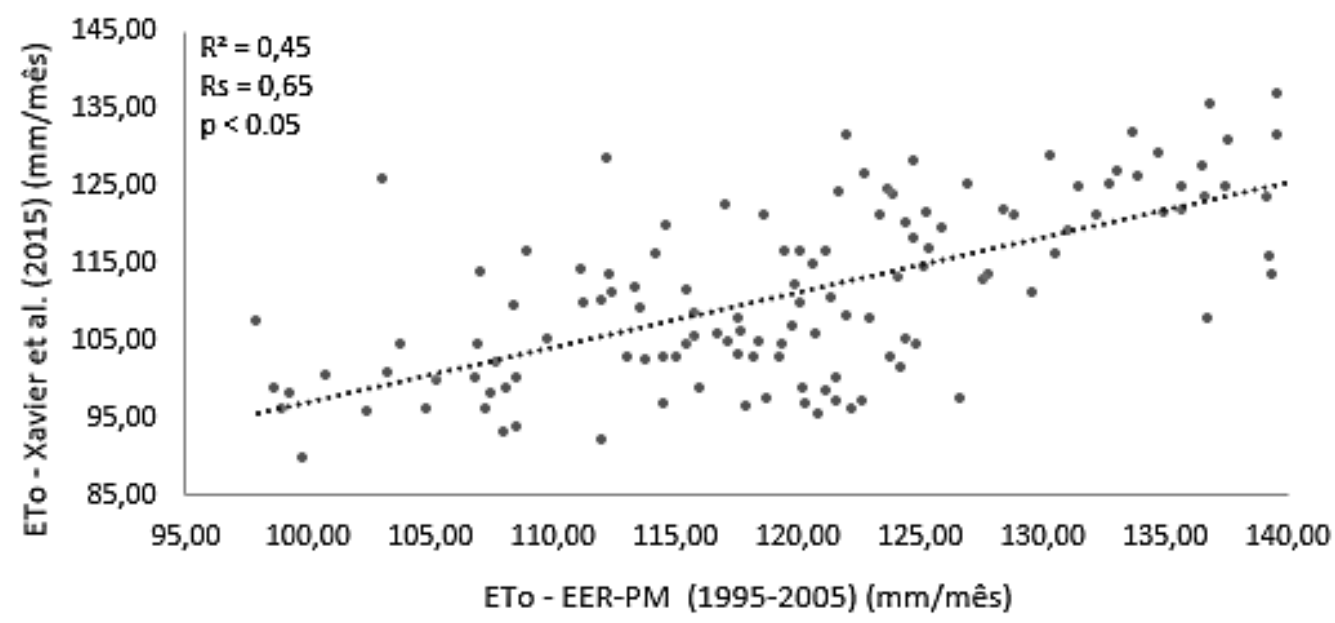

Figura 4 -Correlação entre os valores de ETo simulados pelo modelo EER-PM e os valores observados por Xavier et al. (2015) para o período de 1995 a 2005 . O melhor ajuste linear é demonstrado pela linha tracejada.

A sazonalidade simulada também mostrou-se similar à observada através dos dados fornecidos por Xavier et al. (2015) (Figura 5). Verificamos o aumento da ETo durante a estação seca e diminuição durante a estação chuvosa. Os dados de Xavier et al. (2015) apontam o início da elevação da ETo em junho, ao passo que o modelo EER-PM apontou este crescimento em julho. Ambos as séries de dados detectaram a queda da ETo a partir de novembro. A expressiva elevação da ETo em março detectada através dos dados de Xavier e colaboradores foi apontada pelo modelo EER-PM no mês fevereiro.

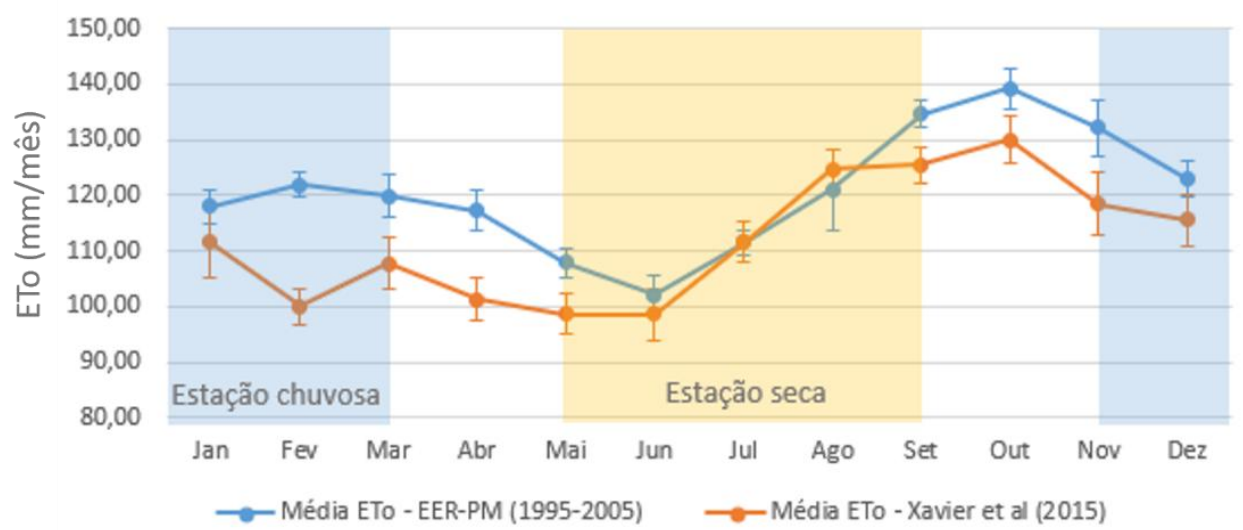

Figura 5 - Médias mensais da ETo projetadas pelo modelo EER-PM e observadas por Xavier et al. (2015) para o período de 1995 a 2005. As barras verticais representam o desvio-padrão.

\subsection{SAZONALIDADE DA ETO NA BACIA AMAZÔNICA BRASILEIRA}

Em grande parte da $B A B$, a estação chuvosa compreende os meses de novembro a março e a estação seca engloba os meses de maio a setembro (Figueroa e Nobre, 1990; Marengo, 1995a, 1995b). Utilizando esta definição, os resultados do modelo EER-PM evidenciam uma marcante sazonalidade nos 
valores da ETo na BAB. Este comportamento é caracterizado pelo aumento da ETo durante a estação seca e diminuição durante a estação chuvosa (Figura 6).

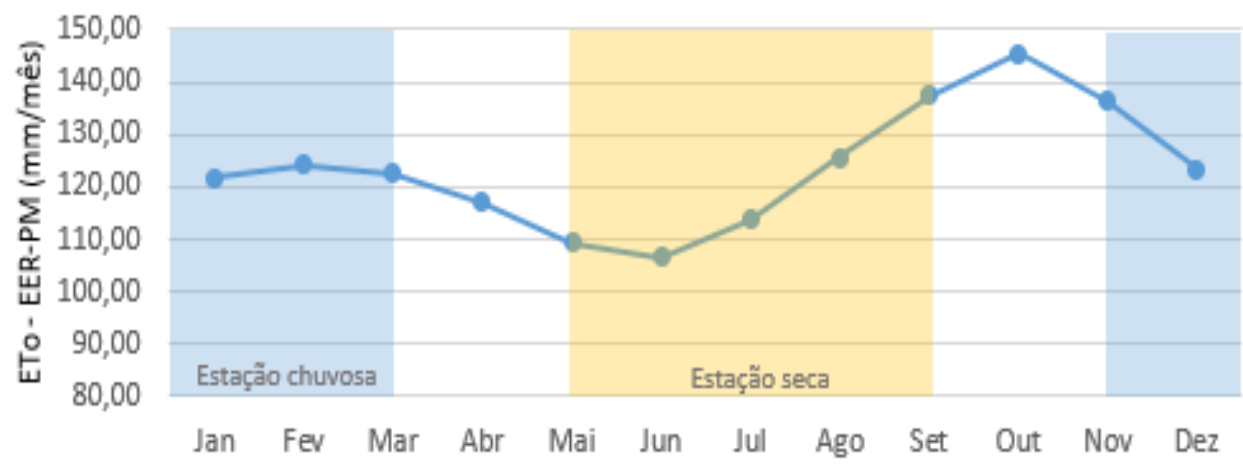

Figura 6 - Médias mensais da ETo na Bacia Amazônica Brasileira estimadas pelo modelo EER-PM para o período projetado (2006-2050).

Verificamos que o aumento da ETo durante a estação seca está relacionado principalmente ao acréscimo de radiação solar e temperatura neste período. Este resultado corrobora com estudos prévios que indicaram estes componentes como as duas principais variáveis afetando a sazonalidade da ETo na Região Amazônica (WERTH e AVISSAR, 2004; SILVA JúNIOR et al., 2017; MAEDA et al., 2017). Ao avaliar as médias mensais dos valores de radiação solar e temperatura, verificamos comportamento semelhante à sazonalidade da ETo (Figura suplementar 4). Dentre as variáveis citadas, o saldo de radiação é o elemento que melhor explica a variação da ETo $\left(R^{2}=0,97\right)$, ou seja, $97 \%$ da variabilidade na ETo é explicada pelo saldo de radiação. Ao passo que, as variações de temperatura explicam $68 \%$ da variabilidade nos valores de ETo. $O$ coeficiente de correlação de Spearman (Rs; SPEARMAN, 1904) indica uma associação positiva $\left(p<10^{-5}\right.$ ) entre o saldo de radiação e a ETo ( $R s=0,98$ ), o mesmo ocorrendo para a correlação com a temperatura (Rs $=0,82$ ) (Figuras suplementares $5 a$ e $5 b)$. Ou seja, o aumento no saldo de radiação e na temperatura levam à um aumento na ETo na BAB.

$\mathrm{Na}$ estação seca, a baixa cobertura de nuvens sob a BAB aumenta a radiação solar incidente na superfície da Floresta (ROSSOW et al., 1991). A radiação não refletida pela superfície (devido ao baixo albedo) é absorvida pelo solo e pela vegetação e posteriormente transformada em calor latente. Portanto, quanto maior a radiação solar incidente, maior a quantidade de energia disponível para a ET (KATUL et al., 2012). É importante ressaltar que a literatura científica também reporta a umidade do solo (em associação com a radiação solar) como um importante fator causal da elevação da ETo durante a estação seca (WERTH e AVISSAR, 2004). As características da vegetação amazônica, em especial as suas raízes profundas, garantem a retenção e absorção da água no solo mesmo durante o período de estiagem (MAEDA et al., 2017; COUTINHO et al., 2018). Este mecanismo mantém as condições necessárias para a ETo durante o período seco.

Notamos a queda significativa nos valores de ETo a partir do início da estação chuvosa, período caracterizado pelo contínuo aumento da precipitação (durante o mês de novembro; Figura 7). Esse resultado sugere que, apesar dos crescentes valores de precipitação e o consequente aumento na umidade do solo, a cobertura de nuvens durante este período dificulta a incidência de raios 
solares sob a superfície, afetando o efetivo processo de ETo (ROSSOW et al., 1991).

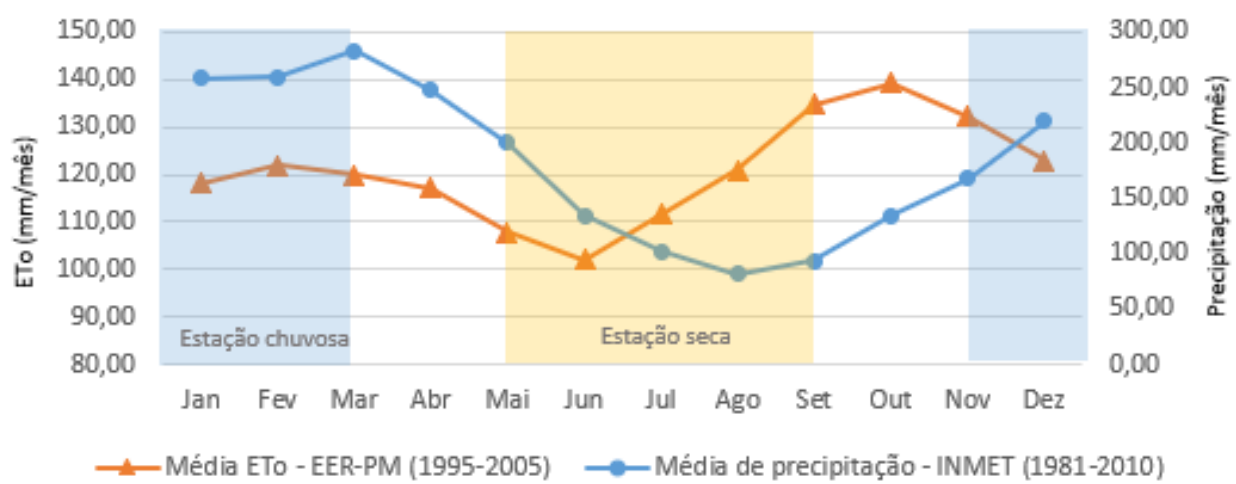

Figura 7 - Normais climatológicas (1981-2010) de precipitação na Bacia Amazônica Brasileira provenientes do Instituto Nacional de Meteorologia (INMET)

\subsection{VARIAÇÃO ESPACIAL DA ETO NA BACIA AMAZÔNICA BRASILEIRA}

Devido à grande extensão geográfica da $B A B$, as variações espaciais nos elementos meteorológicos resultam em variações espaciais da ETo. De fato, nossos resultados demonstraram marcantes gradientes espaciais na região estudada, conforme demonstrado por MAEDA et al., 2017. Os maiores valores são observados na região leste durante o mês de junho, ao passo que, no mês de outubro, os maiores valores são verificados nas células mais a nordeste da BAB. A exceção ocorre no ano de 2050 , quando se estendem para as regiões leste e sudeste. Os menores valores são observados na região noroeste, se estendendo para o sudoeste e sul durante os meses de junho e outubro em todo o período estudado (Figura 8). 

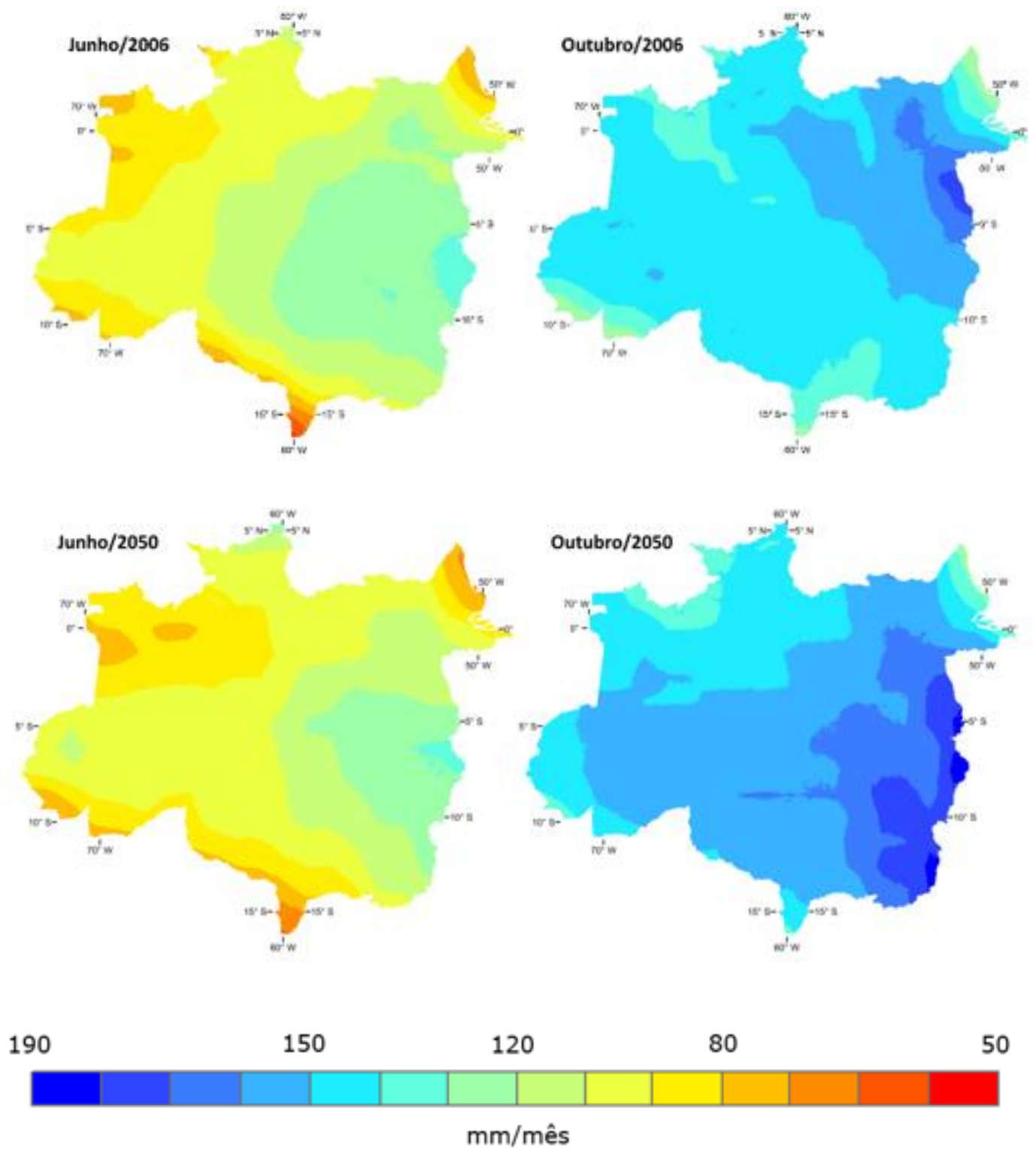

Figura 8 - Variação espacial da ETo na BAB. As estimativas foram calculadas através do modelo EER-PM e utilizando variáveis meteorológicas provenientes das simulações feitas pelo modelo Hadgem2-es (CMIP5).

Embora as configurações dos modelos que elaboram as projeções climáticas dos cenários RCP não incluam dados como taxas de desmatamento ou outras mudanças no uso do solo (MARENGO \& SOUZA, 2018), os nossos resultados sugerem uma relação entre as regiões com elevada temperatura e saldo de radiação (consequentemente com maior ETo), e o gradiente de desmatamento na BAB. Com base neste estudo não podemos afirmar que o desmatamento seja responsável pelo gradiente observado, visto que, mecanismos climáticos de larga escala também podem se encontrar bem correlacionados com este gradiente. Porém, maiores investigações devem ser conduzidas neste sentido. As mudanças no uso e ocupação do solo podem interagir com os mecanismos de larga escala atuantes na Amazônia (LEITE- 
FILHO et al., 2019), intensificando ou reduzindo a ETo. Além de que, as áreas desmatadas possuem maior albedo e consequentemente maior perda de calor latente causando um maior aquecimento superficial (FOLEY et al., 2003).

O acoplamento de um modelo de simulação das mudanças no uso e ocupação do solo ao modelo EER-PM pode conferir maior acurácia às estimativas de ETo. Este avanço poderá colaborar nas investigações dos possíveis efeitos que as mudanças no uso e ocupação do solo (principalmente o desmatamento) dos biomas tropicais, em especial da Amazônia podem provocar no clima, na hidrologia e nos ciclos biogeoquímicos em escalas regionais e globais (Cavalcanti et al., 2009).

\subsection{IMPACTOS DAS MUDANÇAS CLIMÁTICAS (RCP 8.5) NA ETO DA BACIA AMAZÔNICA BRASILEIRA}

As nossas simulações apontam que o contínuo aumento nas concentrações de GEE alcançando um forçamento radiativo de 8,5 watts $/ \mathrm{m}^{2}$ (o que levaria a um aumento na temperatura média global de cerca de $5^{\circ} \mathrm{C}$ até 2100) poderá causar um gradual aumento das médias mensais da ETo na BAB até 2050 (Figura 9). O maior aumento foi identificado em outubro $(+6,18$ $\mathrm{mm} / \mathrm{mês}$ ). Por outro lado, o menor aumento foi identificado em dezembro $(+0,62 \mathrm{~mm} / \mathrm{mês})$. A exceção ocorre apenas no mês de abril, caracterizado por uma pequena diminuição na ETo $(-0,11 \mathrm{~mm} / \mathrm{mês})$.

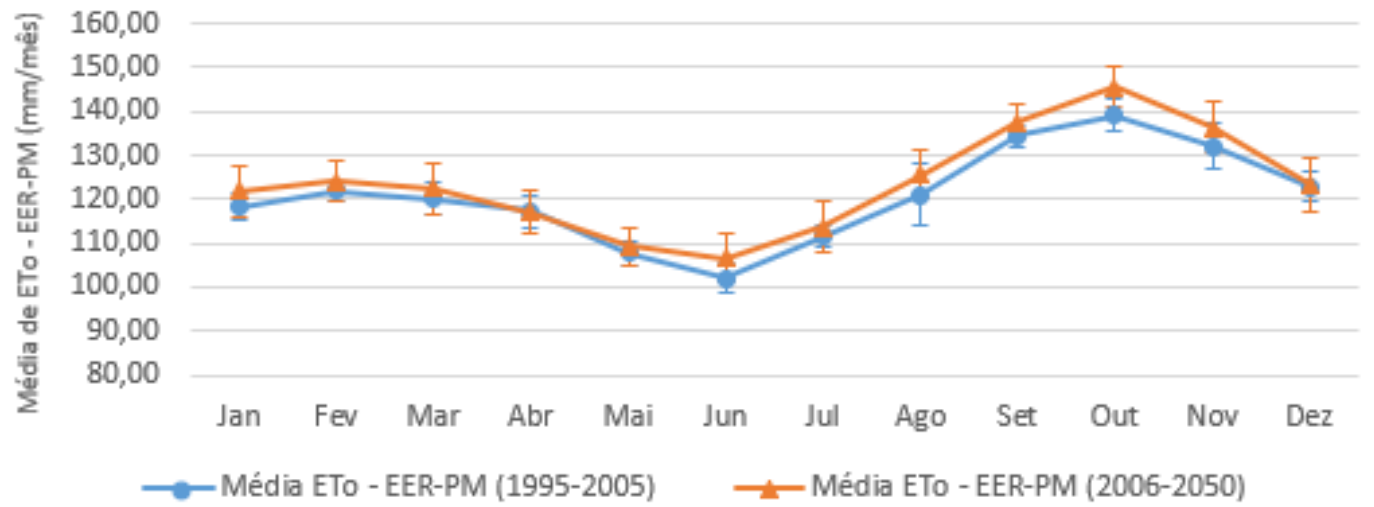

Figura 8 - Médias mensais de ETo observadas e simuladas para a Bacia Amazônica Brasileira através do modelo EER-PM. As barras verticais representam o desvio-padrão.

Ao se utilizar o teste $t$ de Student para comparação de médias provenientes de amostras com tamanhos muito desiguais, é possível que exista uma perda de poder estatístico (WILCOX, 1992). Com um baixo poder estatístico, não poderíamos concluir que o resultado encontrado é definitivo e que estudos maiores podem (ou não) mostrar um resultado igual. Isto acontece no nosso espaço amostral e comprometeria a eficácia do teste. Possuímos 132 e 540 meses para o período simulado e projetado, respectivamente. Buscando contornar este problema, dividimos o período projetado (2006 a 2050) em quatro subperíodos distintos: Os três primeiros intervalos contêm 132 meses (11 anos) e o último intervalo contém 144 (12 anos). Garantindo que o número de meses seja semelhante nas duas amostras, verificamos que diferenças estatisticamente significativas entre as médias de ETo entre o período observado e os subperíodos simulados ocorrem somente a partir do ano de 
2028 (terceiro intervalo de tempo - 2028 a 2038; Tabela 2). Assim, tivemos evidências suficientes para concluir que as médias entre o período observado e os subperíodos simulados são iguais, e que existe um efeito substancial somente apenas a partir de 2028.

Tabela 2 - p-valores do teste $t$ de Student entre as médias da ETo comparando os valores dos subperíodos simulados em relação ao período observado.

\begin{tabular}{|c|c|}
\hline $\begin{array}{lr}\text { Intervalos } & \text { comparado } \\
\text { com o } & \text { período } \\
\text { observado } & \end{array}$ & $\begin{array}{l}\text { p-valor do teste de } \\
\text { diferença }\end{array}$ \\
\hline Intervalo 1 (2006 a 2016) & 0,75 \\
\hline Intervalo 2 (2017 a 2027) & 0,34 \\
\hline Intervalo 3 (2028 a 2038) & 0,01 \\
\hline Intervalo 4 (2039 a 2050) & $1,98.10^{-5}$ \\
\hline
\end{tabular}

Esta diferença estatisticamente significativa a partir de 2028 pode ser justificada pelo aumento gradual nas projeções de temperatura para o cenário RCP 8.5 ao longo do século (Figura 10a; Tabelas suplementares 4 e 5). A temperatura na Amazônia deverá aumentar progressivamente de $1^{\circ} \mathrm{C}$ a $1,5^{\circ} \mathrm{C}$ até 2040 e entre $3^{\circ} \mathrm{C}$ e $3,5^{\circ} \mathrm{C}$ entre 2041 e 2070 (IPCC, 2013; IPCC, 2014; PBMC, 2014). Ressaltamos que, de forma similar à temperatura, as variações nos valores de ETo para os cenários futuros estão bem correlacionadas com as modificações projetadas do saldo de radiação (Figura 10b). Apesar de verificarmos um aumento na temperatura nos próximos 7 anos (período anterior a 2028), de acordo com as nossas simulações, este incremento ainda não causará um efeito significativo nos valores de ETo. Porém, a preocupação com a exacerbação dos efeitos das mudanças climáticas na temperatura e consequentemente na ETo da BAB é urgente já a partir do final desta década. 


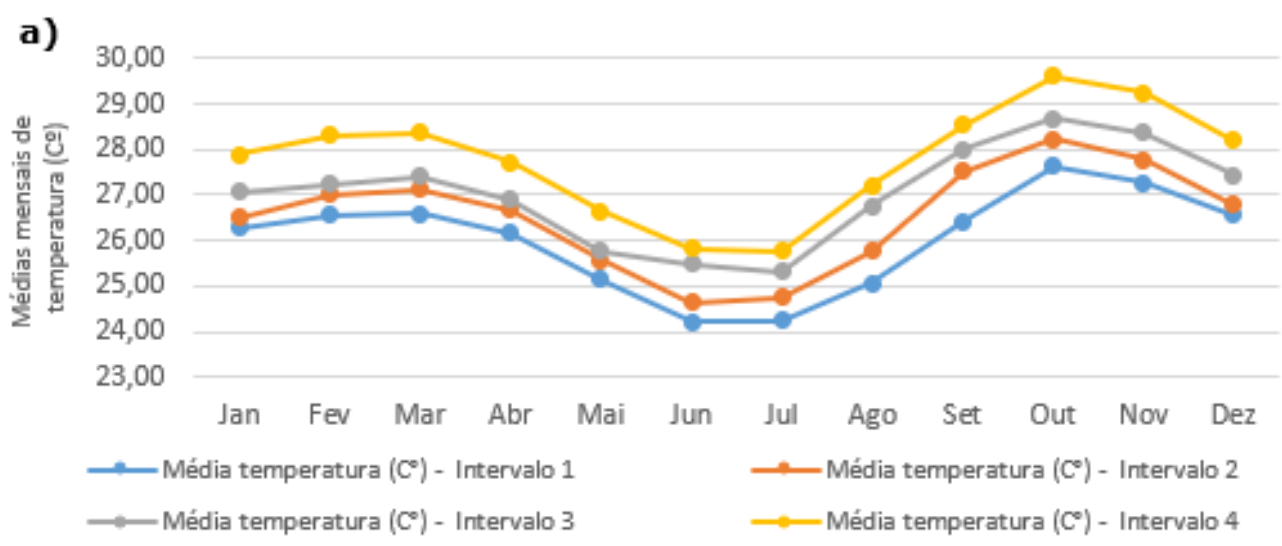

b)

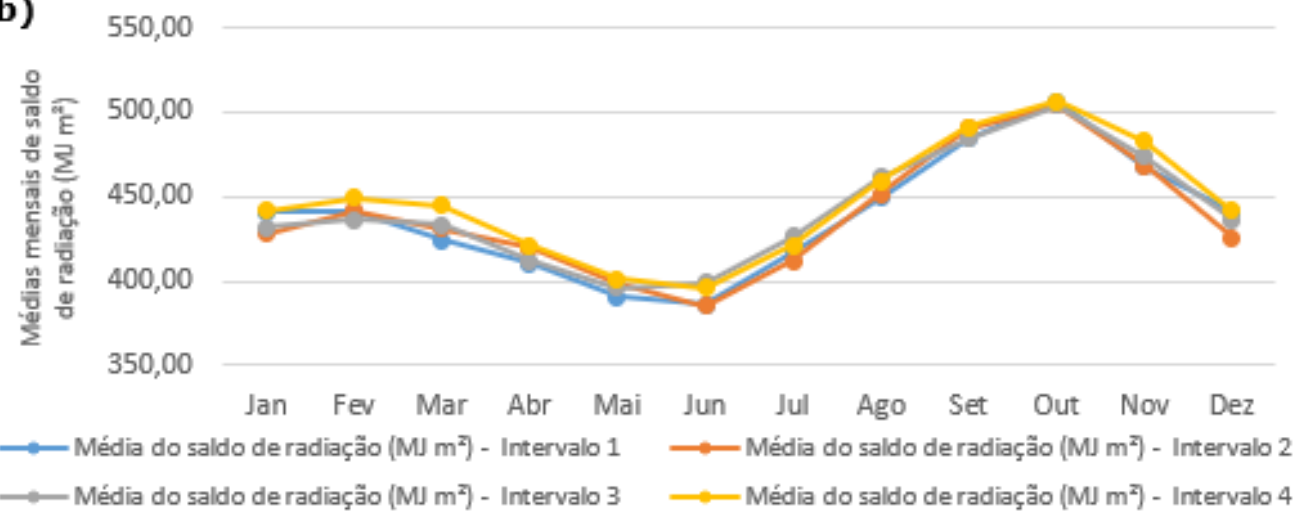

Figura 9 - Médias mensais de temperatura (a) e saldo de radiação (b) para cada os quatro intervalos de tempo do período projetado.

As temperaturas mais elevadas causam maior demanda de ET nas plantas, aumentando o consumo de água e equipamentos para irrigação, comprometendo a rentabilidade do produtor. Para as áreas agrícolas com agricultura de sequeiro este efeito é ainda mais evidente. O aumento da ETo nessas áreas acarretaria em uma acentuação do estresse hídrico durante o período seco. A umidade nas camadas mais superficiais do solo seria retirada e as raízes pouco profundas dos cultivos não conseguiriam acessar a umidade nas camadas mais profundas (CARVALHO, 2011), comprometendo a produção de grãos. Portanto, nossos resultados devem ser considerados na proposição de estratégias de mitigação em um cenário de constante incremento na demanda hídrica devido ao aumento populacional com a necessidade cada vez mais crescente de alimentar toda essa população.

Como mencionado anteriormente, não utilizamos dados projetados de uso e ocupação do solo na BAB na modelagem da ETo. Porém, o desmatamento (e outras mudanças no uso e cobertura do solo), interferem no processo de evapotranspiração através da alteração de parâmetros como a temperatura e o saldo de radiação. Trabalhos anteriores apontaram a diminuição dos valores de evapotranspiração nas áreas afetadas por desmatamento (Dias et al., 2015; Laipelt et al., 2019; Serrão et al., 2019). A substituição da floresta por áreas de pastagem e agricultura acarreta na diminuição da área foliar, levando à uma redução da área potencial de superfície para evaporação e transpiração e também ao aumento do albedo. Há ainda o aumento do escoamento superficial 
e diminuição da infiltração vertical causados pela compactação do solo. Este efeito ocasiona uma redução na disponibilidade hídrica do solo. As raízes dos cultivos são curtas em comparação com as raízes da vegetação florestal e não conseguem alcançar a umidade do solo em grandes profundidades ( $\mathrm{O}^{\prime}$ Connor et al., 2019). Portanto, apesar das projeções do modelo EER-PM indicarem um aumento da ETo no cenário RCP 8.5 até o ano de 2050, o incremento do desmatamento pode anular ou diminuir este acréscimo. Reforçamos então a importância da preservação da floresta amazônica para a manutenção da evapotranspiração e consequentemente na manutenção do ciclo hidrológico em uma perspectiva multi-escala.

\section{CONCLUSÃO}

A comparação entre os valores de ETo simulados e observados demonstrou que o modelo EER-PM é adequado para simular a ETo de forma espacialmente explícita na BAB. Em suma, o EER-PM representa de forma próxima ao real o processo de evapotranspiração na região. A aplicação desta ferramenta em outras áreas das ciências ambientais e climáticas é viabilizada pela versatilidade do método de Penman-Monteith.

Nossas simulações indicam o aumento da ETo durante a estação seca (maio a setembro) e redução durante o período chuvoso (novembro a março). Também verificamos um marcante padrão espacial da ETo com maiores valores na porção leste, se estendendo no sentido norte-sul. Este gradiente acompanha a distribuição dos valores de temperatura e do saldo de radiação e coincide com os padrões de desmatamento. A partir de 2028, as mudanças climáticas projetadas pelo modelo HadGem2-ES no cenário RCP 8.5 podem funcionar como fonte adicional de elevação nos níveis de ETo devido ao aumento da temperatura, em associação com as modificações no saldo de radiação e nos padrões de precipitação.

O conhecimento da água perdida por ET é fundamental para entendermos o balanço hídrico da BAB e regiões adjacentes. O contínuo aumento das emissões de GEE pode, então, acarretar em mudanças significativas no equilíbrio climático em outras regiões do Brasil e América do Sul. Estas mudanças podem afetar diretamente o rendimento das bacias hidrográficas, a umidade atmosférica, a determinação da capacidade de reservatórios, regime de chuvas, e a disponibilidade de água para uso humano, agrícola e industrial.

As nossas simulações poderão auxiliar na compreensão dos efeitos das mudanças climáticas na Amazônia, subsidiando medidas para a mitigação do aumento da concentração de GEE na atmosfera. A mudanças climáticas decorrentes de uma concentração média de GEE correspondente a um forçamento radiativo de 8,5 watts $/ \mathrm{m}^{2}$ são importantes fontes de incremento para demanda de água e devem, portanto, ser evitadas. Nesta perspectiva, indicamos ainda que nossas simulações sejam consideradas como mais uma base para a reflexão visando o alcance dos Objetivos do Desenvolvimento Sustentável (ODS) definidos pela Organização das Nações Unidas, em especial ao ODS 2 que propõe acabar com a fome, alcançar a segurança alimentar e promover a agricultura sustentável até 2030 . 


\section{AGRADECIMENTOS}

Agradecimentos à FAPEMIG (Fundação de Amparo à Pesquisa do Estado de Minas Gerais) pela bolsa de pesquisa concedida que possibilitou o desenvolvimento desse trabalho.

\section{REFERÊNCIAS BIBLIOGRÁFICAS}

ALLEN, R. G. et al. Crop evapotranspiration: Guidelines for computing crop water requirements. Rome: FAO, 1998. 300 p. (FAO - Irrigation and Drainage Paper, 56).

ALVES, L. M. et al. Assessment of a present-day climate simulation of precipitation in south america from CMIP5 climate models. In: Congresso Brasileiro de Meteorologia, 17, 2012, Gramado. Anais do XVII Congresso Brasileiro de Meteorologia.

BRANDO, P. M. et al. The gathering firestorm in southern Amazonia. Science Advances. 6. 2020.

CARVALHO, F. H. (2011). Aquecimento Global - efeitos do aumento da temperatura sobre a evapotranspiração de referência no Brasil. In: Simpósio Brasileiro de Recursos Hídricos, 19, 2011, Maceió. Anais do XIX Simpósio Brasileiro de Recursos Hídricos.

CAVALCANTI, I.F.A. et al. Tempo e clima no Brasil. São Paulo: Oficina de Textos, 2009.

CHRISTENSEN, P. et al. Uncertainty in forecasts of long-run economic growth. Proceedings of the National Academy of Sciences. 115. 2018.

CONCEIÇÃO, M. A. F. Roteiro de cálculo da evapotranspiração de referência pelo método de Penman- Monteith-FAO. Bento Gonçalves: Embrapa Uva e Vinho, 2006, 8 p. (Embrapa Uva e Vinho. Circular Técnica, 65).

COUTINHO, E. C. et al. Variabilidade climática da precipitação na bacia amazônica brasileira. Revista Brasileira de Climatologia, [S.I.], v. 22, 2018. ISSN 2237-8642. Disponível em: <https://revistas.ufpr.br/revistaabclima/article/view/46074>. Acessado em: janeiro de 2020.

CURRIE, D.J. Energy and large-scale patterns of animal-and plant-species richness. The American Naturalist,137, p. 27-49, 1991.

DIAS, L. et al. Effects of land cover change on evapotranspiration and streamflow of small catchments in the Upper Xingu River Basin, Central Brazil. Journal of Hydrology: Regional Studies. 4, Part B. p. 108-122, 2015.

DINIZ-FILHO, J.A.F. et al. Spatial autocorrelation and red herrings in geographical ecology. Global Ecology and Biogeography,12, p. 53-64, 2003.

DIRMEYER, P.A. et al. Comparing evaporative sources of terrestrial precipitation and their extremes in MERRA using relative entropy. Journal of Hydrometeoroly v. 15(1), p. 102-116, 2014. 
ESPINOZA, J. et al. The extreme 2014 flood in South_Western Amazon basin: the role of tropical-subtropical South Atlantic SST gradient. Environmental Research Letters, v. 9, n. 12, p. 1-9, 2014.

FEARNSIDE, P. M. Mudanças climáticas globais e a floresta amazônica. In: Marcos Buckeridge. (Org.). Biologia e Mudanças Climáticas Globais no Brasil. São Paulo: RiMa Editora, 2008, p. 131-150.

FEARNSIDE, P.M. Potential impacts of climatic change on natural forests and forestry in Brazilian Amazonia. Forest Ecology and Management, v. 78(1-3): p. 51-70, 1995.

FIGUEROA, S.N.; NOBRE, C.A. Precipitation distribution over central and western tropical South America. Climanálise, v. 5, p. 36-45, 1990.

FOLEY, J. et al. Green surprise? How terrestrial ecosystems could affect earth's climate. Frontiers in Ecology and the Environment, v.1, 2003, p.38-44.

GULIZIA, C.; CAMILLONI, I. Comparative analysis of the ability of a set of CMIP3 and CMIP5 global climate models to represent precipitation in South America. International Journal of Climatology, v. 35, p. 583-595, 2005.

HASLER, N.; AVISSAR, R. What Controls Evapotranspiration in the Amazon Basin? Journal of Hydrometeorology, v. 8, p. 380-395, 2007.

IPCC. Climate Change 2013: The Physical Science Basis. Contribution of Working Group I to the Fifth Assessment Report of the Intergovernmental Panel on Climate Change. Cambridge University Press, Cambridge, United Kingdom and New York, NY, USA, 2013, 1535 p.

IPCC. Climate Change 2014: Synthesis Report. Contribution of Working Groups I, II and III to the Fifth Assessment Report of the Intergovernmental Panel on Climate Change. Geneva, Switzerland, 2014, 151 p.

KATUL, G. G. et al. Evapotranspiration: A process driving mass transport and energy exchange in the soil-plant-atmosphere-climate system. Reviews of Geophysics, v. 50, 2012.

LAIPELT, L. et al. Impactos das mudanças do uso da terra na evapotranspiração em área transicional entre os biomas Amazônia e Cerrado. In: Simpósio Brasileiro de Recursos Hídricos, Foz do Iguaçu, PR. Anais do XXIII Simpósio Brasileiro de Recursos Hídricos. 2019.

LEITE-FILHO, A.T. et al. The southern Amazon rainy season: The role of deforestation and its interactions with large-scale mechanisms. International Journal of Climatology, p. 1-14, 2019.

MACARTHUR, R.H. and MACARTHUR, J.W. On Bird Species Diversity. Ecology, v. 42, p. 594-598, 1961.

MAEDA, E. et al. Evapotranspiration seasonality across the Amazon Basin. Earth System Dynamics, v. 8, p, 439-454, 2017.

MALHI, Y. et al. (2009). Exploring the likelihood and mechanism of a climatechange-induced dieback of the Amazon rainforest. Proceedings of the National Academy of Sciences of the United States of America, v. 106, p. 20610-2065, 2009. 
MALHI, Y. et al. Climate Change, Deforestation, and the Fate of the Amazon. Science, v. 319, p. 169-172, 2008.

MARENGO J. A.; SOUZA M. Mudanças Climáticas: impactos e cenários para a Amazônia. São Paulo, 2018, 33 p.

MARENGO, J A. Interannual variability of deep convection in the tropical South American sector as deduced from ISCCP C2 data. International Journal of Climatology, n. 9, v. 15, p. 995-1010, 1995a.

MARENGO, J. A. On the hydrological cycle of the Amazon Basin: A historical review and current. Revista Brasileira de Meteorologia, v. 21, p. 1-19, 2006.

MARENGO, J. A. Variations and change in South American streamflow. Climate Change, n. 1, v. 31, p. 99-117, 1995b.

MARENGO, J.A. The characteristics and variability of the atmospheric water balance in the Amazon basin: Spatial and temporal variability. Climate Dynamics, v. 24, p. 11-22, 2005.

MARENGO, J.A.; ESPINOZA, J.C. Extreme seasonal droughts and floods in Amazonia: causes, trends and impacts. International Journal Climatolgy, v. 36, n. 36, p. 1033-1050, 2015.

MONTEITH, J.L. Evaporation and environment. In G.E. Fogg (ed.) Symposium of the Society for Experimental Biology. The State and Movement of Water in Living Organisms, v. 19, p. 205-234, 1965.

O'CONNOR, J. et al. The influence of water table depth on evapotranspiration in the Amazon arc of deforestation. Hydrology and Earth System Sciences Discussions, p. 1-22, 2019.

PBMC. Mitigação das mudanças climáticas. Contribuição do Grupo de Trabalho 3 do Painel Brasileiro de Mudanças Climáticas ao Primeiro Relatório da Avaliação Nacional sobre Mudanças Climáticas. COPPE. Universidade Federal do Rio de Janeiro, Rio de Janeiro, RJ, Brasil, 2014, 463 p.

RODRIGUES, H. O. et al. Dinamica EGO, uma plataforma para modelagem de sistemas ambientais. In: Simpósio Brasileiro de Sensoriamento Remoto, 13, Florianópolis. Anais XIII Simpósio Brasileiro de Sensoriamento Remoto, INPE, p. 3089-3096, 2007.

ROSSOW, W. B. et al. International Satellite Cloud Climatology Project (ISCCP) documentation of cloud data. World Meteorological Organization, n. 266, 1991, $76 \mathrm{p}$.

SALATI, E. et al. Recycling of water in the Amazon Basin: An isotopic study. Water Resourcers Research, n. 5, v. 15, p. 1250-1258, 1979.

SCHWALM, C. R. et al. RCP8.5 tracks cumulative CO2 emissions. Proceedings of the National Academy of Sciences, v. 117, no. 33, p.19656-19657, 2020.

SERRÃO, E. A. O. et al. Influência do uso e cobertura da terra na variabilidade espacial e temporal da evapotranspiração no sudeste da Amazônia, utilizando o modelo SWAT. Revista Ibero Americana de Ciências Ambientais, n. 4, v. 10, p. 134-148, 2019.

SILVA DIAS, M.A.F. et al. Interações entre nuvens, chuvas e a biosfera na Amazônia. Acta Amazônica, n. 2, v. 35, p. 215-222, 2005. 
SILVA JÚNIOR, R. O. DA et al. Three decades of reference evapotranspiration estimates for a tropical watershed in the eastern Amazon. Anais da Academia Brasileira de Ciência, Rio de Janeiro, v. 89, n. 3, p. 1985-2002, 2017.

SOARES-FILHO et al. Forest fragmentation, climate change and understory fire regimes on the Amazonian landscapes of the Xingu headwaters. Landscape Ecology, v. 27, p. 585-598, 2012.

SOARES-FILHO et al. Modeling environmental dynamics with dinamica EGO. Centro de Sensoriamento Remoto, Belo Horizonte, Brasil, 2019. Disponível em: <https://www.csr.ufmg.br/dinamica/dokuwiki/doku.php?id=guidebook_start>. Acesso em: maio de 2020.

SPEARMAN, C.E. The proof and measurement of association between two things. American Journal of Psychology, v. 15, p. 72-101, 1904.

SPRACKLEN, D. V. et al. Observations of increased tropical rainfall preceded by air passage over forests. Nature, v. 489, p. 282-285, 2012.

WERTH, D.; Avissar, R. The regional evapotranspiration of the Amazon. Journal of Hydrometeorology, n. 1, v. 5, p. 100-109, 2004.

WILCOX, R. R. Why Can Methods for Comparing Means Have Relatively Low Power, and What Can You Do to Correct the Problem? Current Directions in Psychological Science, n. 3, v. 1, p. 101-105, 1992.

XAVIER, A. C. et al. Daily gridded meteorological variables in Brazil (19802013). International Journal of Climatology, n. 6, v. 36, p. 2644-2659, 2015.

$\mathrm{XU}, \mathrm{D}$. et al. Estimation of evapotranspiration of Amazon rainforest using the maximum entropy production method. Geophysical Research Letters, n. 3, v. 46, p. $1402-1412,2019$. 